\title{
XÂY DỰNG QUY TRÌNH CÔNG NGHỆ THÀNH LẬP TẬP BẢN ĐỒ HIỆN TRẠNG TÀI NGUYỀ THIÊN NHIÊN TRÊN CƠ SỞ ÚNG DỤNG VIỄN THÁM VÀ GIS
}

\author{
TS. NGUYẼ̃N QUÓC KHÁNH, ThS. VŨ NGỌC PHAN \\ Trung tâm Thông tin và Tư liệu Môi trường
}

\section{Tóm tắt:}

Bài báo trình bày quy trình công nghệ thành lập tập bản đồ hiện trạng tài nguyên thiên nhiên (TNTN) trong phạm vi cấp tỉnh trên cơ sở ứng dụng công nghệ viễn thám và GIS. Quy trình này đã được áp dụng trong thực tế với những hiệu quả nhất định.

\section{1. Đặt vấn đề}

Xây dựng tập bản đồ hiện trạng TNTN nhằm cung cấp các thông tin toàn diện và kịp thời về khu vực giám sát là một trong những nội dung quan trọng của công tác giám sát tài nguyên môi trường. Với những ưu điểm của tư liệu viễn thám như tính cập nhật và đồng bộ về thông tin, khả năng phủ trùm và khái quát hóa tự nhiên các đối tượng, cũng như độ chính xác và khả năng tiếp cận ngày càng gia tăng, công nghệ viễn thám hiện đóng vai trò quan trọng trong công tác giám sát tài nguyên môi trường. Các công cụ phân tích, thể hiện dữ liệu địa lý ngày càng đa dạng và dễ tiếp cận cũng là một trong những yếu tố thúc đẩy ứng dụng công nghệ GIS trong công tác thành lập bản đồ. Việc kết hợp công nghệ viễn thám và GIS trong xây dựng tập bản đồ hiện trạng TNTN có thể đảm bảo tính kế thừa, rút ngắn thời gian thi công so với công nghệ truyền thống trước đây, tăng độ chính xác, tính logíc, hiện thời của thông tin bản đồ.

\section{Bản đồ hiện trạng TNTN}

Bản đồ hiện trạng TNTN là bản đồ chuyên đề mà nội dung thể hiện các nhóm đối tượng TNTN nhằm phục vụ công tác quản lý, giám sát, quy hoạch và các nhiệm vụ liên quan khác.

Công tác điều tra, khảo sát và thành lập bản đồ hiện trạng TNTN đã được tiến hành ở Việt Nam từ nhiều năm nay. Trong phạm vi cấp tỉnh, việc thành lập các bản đồ này chủ yếu

Ngày nhận bài: 15/10/2015 mới được tiến hành theo từng loại tài nguyên riêng lẻ. Thực tế, do công tác thành lập bản đồ hiện trạng TNTN được tiến hành ở những thời kỳ khác nhau và tuân theo từng quy định, yêu cầu cụ thể nên các bản đồ này có chất lượng không đồng đều. Với một số loại TNTN có sự biến động nhanh, bản đồ được thành lập trên cơ sở sử dụng các tài liệu mà thường chúng đã không còn phản ánh đúng hiện trạng ở thời điểm hoàn thành, do vậy các bản đồ này ít có ý nghĩa trong thực tế.

Bản đồ hiện trạng TNTN có thể được thành lập bằng một trong các phương pháp: phương pháp xử lý và giải đoán ảnh viễn thám; phương pháp phân tích bằng GIS; phương pháp điều tra, đo đạc thực địa; phương pháp biên vẽ từ bản đồ. Mỗi phương pháp đều có những ưu, nhược điểm riêng, và việc lựa chọn phương pháp là tùy thuộc vào mục đích sử dụng cũng như tư liệu và điều kiện kỹ thuật. Việc ứng dụng công nghệ viễn thám và công nghệ GIS sẽ giúp cho việc xây dựng tập bản đồ hiện trạng TNTN được thực hiện một cách nhanh chóng, chính xác và đồng bộ, đặc biệt hiệu quả đối với một số nhóm tài nguyên như tài nguyên nước, tài nguyên đất và tài nguyên đa dạng sinh học.

\section{Quy trình công nghệ thành lập tập bản đồ hiện trạng TNTN trên cơ sở ứng dụng viễn thám và GIS}

\subsection{Quy định chung}

Ngày chấp nhận đăng: 30/10/2015 
Quy định về thành lập tập bản đồ hiện trạng TNTN được xây dựng dựa trên những yêu cầu kỹ thuật cơ bản cho việc thành lập bản đồ địa hình do Bộ Tài nguyên và Môi trường đã ban hành.

\subsubsection{Cơ sở toán học}

Cơ sở toán học của tập bản đồ hiện trạng TNTN được quy định cụ thể như sau:

E-líp-xô-ít quy chiếu WSG-84 với kích thước: Bán trục lớn: 6.378.137 m; độ dẹt: 1/298, 257223563.

Lưới chiếu bản đồ: để đảm bảo tính thống nhất trong phạm vi cả nước thì phương án được lựa chọn đó là lưới chiếu hình trụ ngang đồng góc, kinh tuyến trục $105^{\circ}$, hệ số điều chỉnh tỷ lệ biến dạng chiều dài $\mathrm{k}_{0}=0,9996$.

Tỷ lệ của tập bản đồ hiện trạng TNTN (cấp tỉnh) được lựa chọn dựa vào kích thước, diện tích, hình dạng của đơn vị hành chính, cụ thể như sau: bản đồ được thành lập ở tỷ lệ 1:25.000 nếu diện tích tự nhiên dưới 100.000 ha; tỷ lệ 1:50.000 nếu diện tích tự nhiên từ 100.000 ha đến 350.000 ha; tỷ lệ 1:100.000 nếu diện tích tự nhiên trên 350.000 ha.

\subsection{2. Độ chính xác hình học}

Độ chính xác của tập bản đồ hiện trạng TNTN được quy định cụ thể như sau:

Cơ sở khống chế trắc địa bảo đảm việc thành lập bản đồ TNTN các tỷ lệ là các điểm đo đạc cơ sở quốc gia bao gồm các điểm tọa độ và độ cao Nhà nước từ hạng 3 trở lên được chuyển nguyên từ bản đồ địa hình cùng tỷ lệ;

Các yếu tố nội dung nền địa lý phải đảm bảo được giữ nguyên vị trí như trên bản đồ địa hình được sử dụng làm nền;

Các yếu tố nội dung chuyên đề cho phép thể hiện trong hạn sai bằng hoặc lớn hơn đến 2 lần hạn sai của các yếu tố nội dung trên bản đồ địa hình được sử dụng làm nền.

\subsubsection{Mức độ chi tiết về nội dung bản đồ}

Mức độ chi tiết được thể hiện thông qua hệ phân loại của loại bản đồ cần thành lập. Về mặt hình học thì các yếu tố nội dung chuyên môn được thể hiện với diện tích nhỏ nhất từ 0,5-9 mm² tùy theo từng đối tượng.

Dưới đây là ví dụ về hệ phân loại nội dung chuyên đề Hệ sinh thái được sử dụng trong dự án "Xây dựng cơ sở dữ liệu và hệ thống thông tin tổng hợp phục vụ quản lý tổng hợp đới bờ vùng Bắc Trung Bộ và Duyên hải Trung Bộ" (xem bảng 1)

\subsubsection{Tài liệu dùng để thành lập bộ bản đồ}

Tài liệu dùng để thành lập bộ bản đồ hiện trạng TNMT là các loại tư liệu viễn thám (ảnh máy bay, ảnh vệ tinh Landsat, ảnh vệ tinh Spot...), bản đồ địa hình, chuyên đề (bản đồ hiện trạng sử dụng đất...) và các tài liệu khác đảm bảo các quy chuẩn kỹ thuật quy định và có cơ sở pháp lý rõ ràng.

\subsection{Quy trình công nghệ thành lập tập bản đồ hiện trạng TNTN}

Bước 1: Công tác chuẩn bị

+ Xây dựng đề cương:

Công việc đầu tiên trong giai đoạn chuẩn bị là xây dựng đề cương. Khác với các trường hợp thành lập bản đồ theo các tư liệu có săn hoặc tài liệu thống kê, bản đề cương của tập bản đồ hiện trạng TNTN ở giai đoạn này còn mang rõ nét tính chất định hướng, nhất là phần nội dung và chú giải của bản đồ, vì việc khảo sát đối tượng nghiên cứu trong giai đoạn này mới chỉ mang tính chất sơ bộ. Các đặc trưng cần phản ánh trên bản đồ chỉ có thể xác định được đầy đủ sau từng giai đoạn đã nêu trên sơ đồ. Vì vậy trong giai đoạn tiếp theo, dựa vào kết quả khảo sát cụ thể cần hoàn chỉnh phần nội dung và bản chú giải của từng loại bản đồ.

+ Thu thập và đánh giá tư liệu:

Mức độ đầy đủ, chính xác của việc thu thập và đánh giá, phân loại tư liệu ảnh hưởng rất lớn đến chất lượng, thời gian và kinh phí thành lập bản đồ. Công tác này sẽ thực sự hiệu quả 
Bảng 1: Hệ phân loại nội dung bản đồ chuyên đề Hệ sinh thái (cấp tỉnh)

\begin{tabular}{|c|c|c|c|c|c|}
\hline STT & Nội dung & Loại mã & STT & Nội dung & Loại mã \\
\hline 1 & HẸ SINH THÁl TRÊN CẠN & & 2.5 & Hệ sinh thái nước lọ̣ nhân tác & \\
\hline 1.1 & Hệ sinh thái nhân tác trên cạn & & 2.5 .1 & Vùng nuôi trồng thủy sản cửa sông & TLS \\
\hline 1.1.1 & Đồng cỏ & & 2.5 .2 & Vùng làm muối & LMS \\
\hline 1.1 .2 & Rừng trồng & RTG & 2.5 .3 & Vùng trồng cói & SOC \\
\hline 1.1 .3 & Vùng nông nghiệp thâm canh chuyên lúa & LUC & 2.5 .4 & Vùng nuôi trồng thủy sản trong đầm phá & TLP-TLS \\
\hline 1.1 .4 & Vùng chuyên trồng cây lâu năm & LTC & 2. 6 & Hệ sinh thái nước lọ̣ tự nhiên & \\
\hline 1.1 .5 & Vùng chuyên trồng cây hàng năm & HTC & 2. 6.1 & Đầm phá & $\mathrm{DPH}$ \\
\hline 1.1 .6 & Vùng nông nghiệp phân tán & NPT & 2. 6.2 & Vùng đất trũng ngập nước lợ, mặn cửa sông & DMS \\
\hline 1.1 .7 & Vùng đô thị & VDT & 2. 6.3 & Cồn đảo cửa sông & CDC \\
\hline 1.1 .8 & Vùng nông thôn & VNT & 2. 6.4 & Vùng nước cửa sông & VCS \\
\hline 1.1 .9 & Khu công nghiệp và chuyên dùng khác & CND & 2. 6.5 & Bãi ngập cửa sông & $\operatorname{SCSN}$ \\
\hline 1.1.10 & Vùng khai thác, đào bới & SKT & 2. 6.6 & Bãi bồi cửa sông & VBS \\
\hline 1.2 & Hệ sinh tụ̣ nhiên trên cạn & & 2. 6.7 & Rừng ngập mặn cửa sông & RMS \\
\hline 1.2 .1 & Đất trống, đồi trọc & & 2.7 & Các hệ sinh thái nước mặn nhân tác ven bò̀ & \\
\hline 1.2 .2 & Cồn cát, bãi cát & & 2. 7.1 & Vùng nuôi trồng thủy sản ven biển & TMB \\
\hline 1.2 .3 & Rừng cây bụi & & 2. 7.2 & Vùng làm muối ven biển & LMB \\
\hline 1.2 .4 & Rừng rậm nhiệt đới & RRN & 2. 7.3 & Vùng trồng cói ven biển & $\mathrm{BCO}$ \\
\hline 1.2 .5 & Rừng thưa nhiệt đới & RTH & 2. 8 & Các hệ sinh thái nước mặn tụ̣ nhiên ven bờ & \\
\hline 1.2 .6 & Trảng cỏ, cây bụi & TCS & 2. 8.1 & Đảo nhỏ & DNH \\
\hline 1.2 .7 & Núi đá & & 2. 8.2 & Cỏ biển, rong, tảo biển & $\mathrm{COB}$ \\
\hline 2 & HẸ SINH THÁI DƯỚI NƯỚC & & 2. 8.3 & Biển nông ven bở ( dưới $6 \mathrm{~m}$ khi triều kiệt) & VBN \\
\hline 2.1 & Hệ sinh thái nước ngọt chảy nhân tác & & 2. 8.4 & Vũng, vinh nhỏ (tùng, áng) & VUV \\
\hline 2.1 .1 & Hồ chứa nước nhân tạo & $\mathrm{HAC}$ & 2. 8.5 & Vùng bãi triều thấp & VTC \\
\hline 2.1 .2 & Kênh, mương & KRM & 2. 8.6 & Vùng bãi bồi ven biển & VBB \\
\hline 2.1 .3 & Vùng nuôi thủy sản trên sông & TNC & 2. 8.7 & Bãi biển cát & $\mathrm{BBC}$ \\
\hline 2. 2 & Hệ sinh thái nước ngọt chảy chảy tự nhiên & & 2. 8.8 & Bờ biển bãi đá, vách đá & BVD \\
\hline 2.2 .1 & Cù lao sông & CLS & 2. 8.9 & Rừng ngập mặn ven biển & RMB \\
\hline 2.2 .2 & Sông, suối có nước thường xuyên & sox & 2. 8.10 & Vùng đất trũng ngập nước mặn ven biển & DMB \\
\hline 2.2 .3 & Sông, suối có nước theo mùa & SOM & 2. 9 & Các hệ sinh thái nước mặn tụ̣ nhiên vùng khơi & \\
\hline 2.2 .4 & Bãi ngập ven sông & VSN & 2. 9.1 & Biển nông ven bở ( dưới $6 \mathrm{~m}$ khi triều kiệt) & BIK \\
\hline 2.3 & Hệ sinh thái nước ngọt tĩnh nhân tác & & 2. 9.2 & Vịnh lớn & VBL \\
\hline 2.3 .1 & Hồ, ao nhân tạo & HAT & 3 & CÁC YÉU TÓ BỎ TRỢ NỘI DUNG CHUYÊN MÔN & \\
\hline 2.3 .2 & Vùng nuôi thủy sản nước ngọt & TNT & 3.1 & Ban quản lý Vườn quốc gia & \\
\hline 2.3 .3 & Ruộng trũng (trồng lúa hoặc kết hợp nuôi thủy sản & LTS & 3.2 & Ranh giới Vườn quốc gia- Khu bảo tồn & \\
\hline 2.4 & Hệ sinh thái nước ngọt tĩnh tự nhiên & & 3.3 & Vùng núi đá vôi & VNDV \\
\hline 2.4 .1 & Hồ có nước theo mùa & HNM & 3.4 & Ranh giới vùng đất trũng ngập nước & \\
\hline 2.4 .2 & Hồ có nước thường xuyên & HNT & 3.5 & Ranh giới biển nông ven bờ & \\
\hline 2.4 .3 & Vùng đất trũng ngập nước ngọt & NNN & 3.6 & Ranh giới các vùng chuyên môn & \\
\hline
\end{tabular}


nếu ngay từ đầu đã xây dựng được kế hoạch hợp lý.

+ Xây dựng thiết kế kĩ thuật:

Bản thiết kế này được xây dựng trên cơ sở của đề cương và kết quả khảo sát về thông tin tư liệu, điều kiện tự nhiên, kinh tế xã hội khu vực nghiên cứu, dựa theo các quy định về kỹ thuật và định mức kinh tế hiện hành. Bản thiết kế do cơ quan có thẩm quyền phê duyệt, được sử dụng trong suốt quá trình thi công, là cơ sở để kiểm tra, nghiệm thu các sản phẩm đã hoàn thành và thanh quyết toán công trình. Tuy nhiên do nội dung của bản đồ chỉ thực sự hoàn thiện sau quá trình khảo sát ngoại nghiệp nên sẽ còn tồn tại những vấn đề cần bổ sung. Nội dung bổ sung này sẽ phải được giải trình hợp lý và có xác nhận của cấp có thẩm quyền.

\section{Bước 2:}

\section{Xử lý ảnh viễn thám}

Tư liệu ảnh viễn thám qua các công đoạn xử lý số để tạo ra những sản phẩm bình đồ ảnh phù hợp với các phương pháp khai thác thông tin khác nhau nhằm cung cấp tối đa lượng thông tin về vị trí phân bố, đặc điểm cấu trúc và phần nào tính chất của các đối tượng mặt đất. Quá trình này thực chất là cả một quy trình sản xuất, trong quy trình công nghệ này chỉ trình bày những công đoạn sản xuất chính sau: lập mô hình số độ cao; đo khống chế ảnh; nắn chỉnh hình học; xử lý phổ, tăng cường chất lượng ảnh, thành lập bình đồ ảnh, phân loại ảnh tự động.

\section{Bước 3 :}

Thành lập bản đồ nền là quá trình biên tập nội dung bản đồ địa hình (tổng hợp, lấy bỏ nội dung theo quy định), kết hợp với suy giải ảnh viễn thám, bổ sung các thông tin mới nhất nhằm chỉnh sửa các lớp thông tin cơ bản: Thủy hệ, địa hình, giao thông, dân cư, địa giới hành chính để xây dựng các lớp thông tin nền địa lý chung của khu vực thành lập bản đồ. (xem hinh 1)

\section{Bước 4:}

Điều vẽ nội nghiệp:

Trên cơ sở các quy định kỹ thuật, các yếu tố nội dung đã tách từ tư liệu ảnh vệ tinh, được trình bày tổng hợp trên một file dữ liệu, nhằm đảm bảo yêu cầu về tính chỉnh hợp, đồng bộ của bộ bản đồ. Công tác điều vẽ nội nghiệp bao gồm:

+ Sử dụng toàn bộ các tư liệu đã được thu thập để điều vẽ nội nghiệp, tuân thủ các yêu cầu kỹ thuật đã đề ra.

+ Đánh dấu các đối tượng, các khu vực cần xác minh ngoại nghiệp.

Bước 5:

Kiểm tra ngoại nghiệp

Là quá trình kiểm tra lại kết quả điều vẽ nội nghiệp và bổ sung các thông tin trên tư liệu ảnh viễn thám không thể xác định trong nội nghiệp. Ngoài ra còn có nhiệm vụ thu thập thêm các tài liệu chuyên ngành khác.

Bước 6 :

Chuyển vẽ, số hoá

Kết quả điều vẽ bổ sung ngoại nghiệp và kết quả xử lý tài liệu bản đồ được chuyển vẽ và số hoá bổ sung vào kết quả điều vẽ nội nghiệp. Sau quá trình sửa chữa bổ sung ngoại nghiệp, các lớp thông tin được biên tập lại theo quy định dữ liệu số trong phần mềm MicroStation.

Bước 7 :

Chuẩn hoá

Quá trình chuẩn hoá dữ liệu các lớp thông tin chuyên đề được thực hiện trong phần mềm MicroStation và ArcGis.

Bước 8:

Xây dựng cơ sở dữ liệu

Quá trình này được thực hiện trong phần mềm ArcGis, dữ liệu đầu vào là kết quả điều vẽ tổng hợp các yếu tố nội dung và các thông tin thuộc tính khác. 


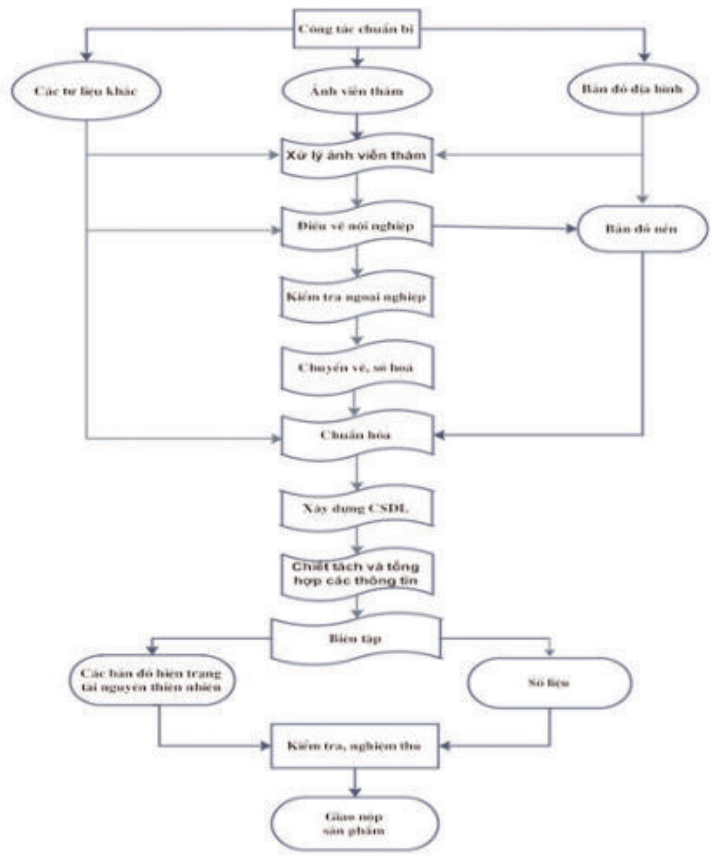

Hình 1: So đồ trình thành lập tập bản đồ hiện trạng TNTN trên cơ sở ứng dụng công nghệ viễn thám và GIS

\section{Bước 12:}

Giao nộp sản phẩm:

Sản phẩm được giao dưới dạng bản đồ số, bản đồ in, báo cáo thuyết minh từng bản đồ chuyên đề, báo cáo tổng kết ghi trong đĩa $C D$.

\section{Kết quả và thảo luận}

Trên cơ sở các ưu điểm của công nghệ viễn thám và GIS, cùng những yêu cầu kỹ thuật cơ bản cho việc thành lập bản đồ địa hình và bản đồ chuyên đề do Bộ Tài nguyên và Môi trường đã ban hành, tác giả đã đưa ra quy trình công nghệ bao gồm 12 bước để thành lập bộ bản đồ hiện trạng TNTN. Các bước của quy trình chủ yếu được xử lý nội nghiệp tuy nhiên quá trình kiểm tra ngoại nghiệp đã khẳng định được hiệu quả của phương pháp này. Việc xử lý tổng hợp các thông tin cùng một lúc và phân tách các lớp thông tin nhờ sự hỗ trợ của công nghệ GIS đã tăng độ chính xác, tính chỉnh hợp của thông tin mà các phương pháp thành lập bản đồ trước đây mất rất nhiều thời gian để kiểm tra

\section{Bước 9:}

Chiết tách và tổng hợp các thông tin

Trên cơ sở các lớp thông tin đã gán thuộc tính sẽ chiết tách và tổng hợp các thông tin theo nội dung của từng bản đồ để chuyển sang khâu biên tập và in ấn.

Bước 10:

\section{Biên tập}

Sau khi có đủ các lớp thông tin của từng bản đồ, tiến hành biên tập, trình bày nội dung của từng bản đồ theo thiết kế kỹ thuật.

\section{Bước 11:}

Kiểm tra, nghiệm thu. Kết quả kiểm tra, nghiệm thu phải được lập biên bản theo Thông tư số 02/2007/TT-BTNMT ngày 12 tháng 02 năm 2007 của Bộ Tài nguyên và Môi trường về hướng dẫn kiểm tra, thẩm định và nghiệm thu công trình, sản phẩm đo đạc và bản đồ.

và chỉnh hợp nội dung bản đồ.

Quy trình được áp dụng trong nhiều nhiệm vụ, dự án mà Trung tâm Thông tin và Tư liệu Môi trường- Tổng cục Môi trường đã thực hiện góp phần nâng cao hiệu quả, giảm bớt thời gian và kinh phí ngoại nghiệp, thời gian sửa chữa, chỉnh hợp nội dung các bản đồ so với các phương pháp truyền thống.

Dưới đây là chú giải nội dung chuyên đề bản đồ Hệ sinh thái được thành lập theo "Quy trình công nghệ thành lập tập bản đồ hiện trạng TNTN trên cơ sở ứng dụng viễn thám và GIS", bản đồ này là sản phẩm của dự án "Xây dựng cơ sở dữ liệu và hệ thống thông tin phục vụ quản lý tổng hợp đới bờ vùng Bắc Trung Bộ và Duyên hải Trung Bộ" của Tổng cục Môi trường. (xem hinh 2)

Để có thể thành lập các bản đồ theo quy trình công nghệ đã đưa ra một cách thuận lợi, thì điều quan trọng là phải xây dựng được hệ phân loại một cách hợp lý. Xây dựng một hệ 
phân loại chung, thống nhất như vậy đòi hỏi phải có sự kết hợp chặt chẽ của các chuyên gia ở nhiều lĩnh vực.
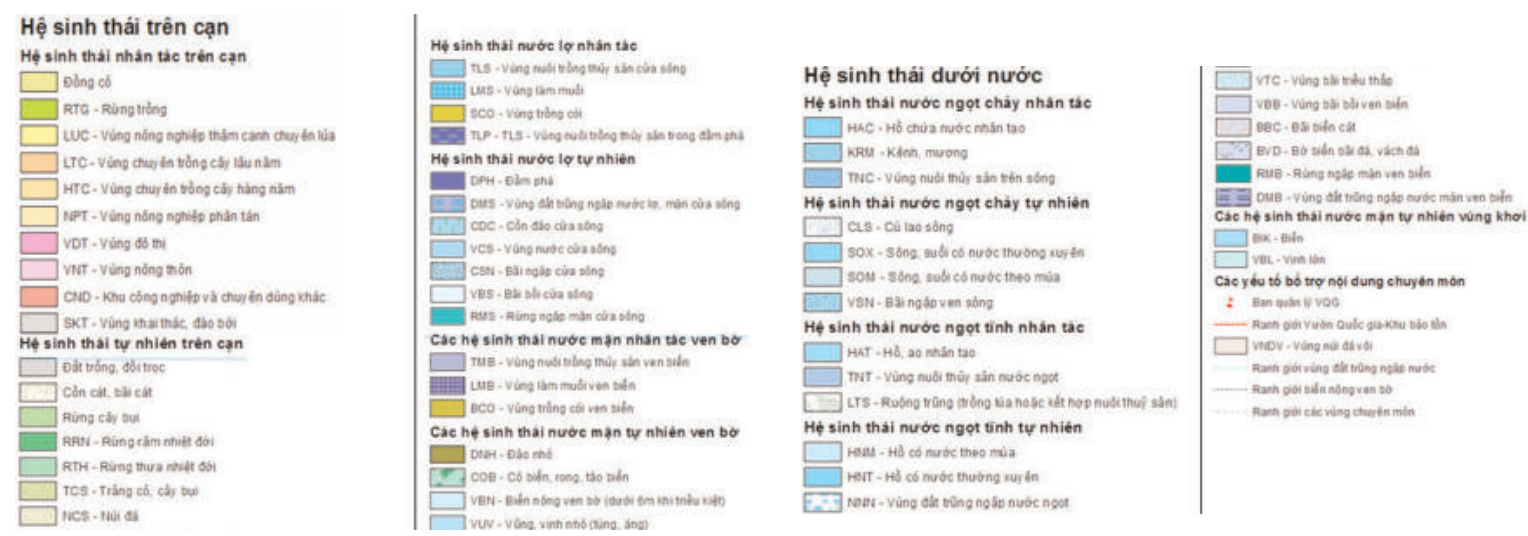

Hình 2: Chú giải nội dung chuyên đề bản đồ Hệ sinh thái

\section{Kết luận}

1. Ứng dụng công nghệ viễn thám và GIS là giải pháp hiệu quả, đáp ứng được yêu cầu thông tin đồng bộ, hiện thời của bộ bản đồ hiện trạng tài nguyên nước, bản đồ hiện trạng tài nguyên đất và bản đồ hiện trạng tài nguyên đa dạng sinh học.

2. Quy trình đã đưa ra phù hợp với các quy định hiện hành, có tính khả thi, đảm bảo yêu cầu tiến độ đặt ra và có thể áp dụng rộng rãi vào thực tế. 0

\section{Tài liệu tham khảo}

[1]. Remote sensing and GIS integation: Towards intelligent imagery within a spatial data infrastructure. Mohamed Abdelrahim - October 2001. Geodesy and geomatics engineering UNB Technical report No.210.

[2]. Quy định kỹ thuật hiện chỉnh bản đồ địa hình quốc gia tỷ lệ 1: 10.000, 1:5.000 và 1: 50.000 bằng ảnh vệ tinh.

[3]. Quyết định số 83/2000/QĐ-TTg ngày 12/7/2000 của Thủ tướng Chính phủ về sử dụng Hệ quy chiếu và Hệ tọa độ quốc gia Việt Nam.

[4]. Thông tư 973/2001/TT-TCĐC của Tổng cục địa chính ngày 20/06/2001 về hướng dẫn áp dụng hệ quy chiếu và hệ tọa độ quốc gia VN-2000.

[5]. Thông tư 17/2011/TT-BTNMT của Bộ Tài nguyên Môi trường Quy định quy trình kỹ thuật thành lập bản đồ môi trường (không khí, nước mặt lục địa, nước biển). $\mathrm{O}$

\section{Summary}

\section{Process technology establish atlas of natural resources based on applications remote sensing and GIS}

Dr. Nguyen Quoc Khanh, MSc Vu Ngoc Phan

This article proposes workflow to build maps of natural resources based on remote sensing and GIS application. Actually, this workflow has been successfully realised to compile medium scale maps of natural resources .O 